$11-1-2006$

\title{
Long-Term Trends in the National Demand, Supply, and Shortage of Special Education Teachers
}

\author{
Ed Boe \\ Univer. of Pennsylvania, boe@gse.upenn.edu
}

Follow this and additional works at: https://repository.upenn.edu/gse_pubs

\section{Recommended Citation}

Boe, E. (2006). Long-Term Trends in the National Demand, Supply, and Shortage of Special Education Teachers. Retrieved from https://repository.upenn.edu/gse_pubs/185

Postprint version. Published in Journal of Special Education, Volume 40, Issue 3, November 2006, pages 138-150.

Publisher URL: http://dx.doi.org/10.1177/00224669060400030201

This paper is posted at ScholarlyCommons. https://repository.upenn.edu/gse_pubs/185

For more information, please contact repository@pobox.upenn.edu. 


\title{
Long-Term Trends in the National Demand, Supply, and Shortage of Special Education Teachers
}

\author{
Abstract \\ With a focus on both teacher quality and quantity at the national level, this research examined longterm \\ trends in the demand, supply, and shortage of special education teachers for 16 school years, from 1987/ \\ 1988 through 2002/2003. These trends were based on data published in annual reports to Congress on \\ the implementation of the Individuals with Disabilities Education Act by the Office of Special Education \\ Programs, U.S. Department of Education. Rapid growth in teacher demand for students with disabilities \\ aged 3-5 years was found, whereas the growth in teacher demand for students aged 6-21 years was \\ more gradual and paralleled the rate of growth in teacher demand in general education. Although teacher \\ demand was mostly satisfied by growth in the supply of fully certified teachers, the shortage of fully \\ certified teachers for students with disabilities aged 6-21 years has been chronic since 1987/1988 and \\ has increased annually, from $7.4 \%$ in $1993 / 1994$ to $13.4 \%$ in $2002 / 2003$ (a shortage of approximately \\ 54,000 special education teachers, including estimated vacant positions).

\section{Comments} \\ Postprint version. Published in Journal of Special Education, Volume 40, Issue 3, November 2006, pages \\ 138-150. \\ Publisher URL: http://dx.doi.org/10.1177/00224669060400030201
}




\title{
Long-Term Trends in the National Demand, Supply, and Shortage of Special Education Teachers
}

\author{
Erling E. Boe \\ University of Pennsylvania \\ Graduate School of Education
}

\begin{abstract}
With a focus on both teacher quality and quantity at the national level, this research examined longterm trends in the demand, supply, and shortage of special education teachers for 16 school years, from 1987/1988 through 2002/2003. These trends were based on data published in annual reports to Congress on the implementation of the Individuals with Disabilities Education Act by the Office of Special Education Programs, U.S. Department of Education. Rapid growth in teacher demand for students with disabilities aged 3-5 years was found, whereas the growth in teacher demand for students aged 6-21 years was more gradual and paralleled the rate of growth in teacher demand in general education. Although teacher demand was mostly satisfied by growth in the supply of fully certified teachers, the shortage of fully certified teachers for students with disabilities aged 6-21 years has been chronic since 1987/1988 and has increased annually, from $7.4 \%$ in 1993/1994 to 13.4\% in 2002/2003 (a shortage of approximately 54,000 special education teachers, including estimated vacant positions).
\end{abstract}

The relationship between teacher supply and demand has been described as a "puzzle" based on "the interaction between quality and quantity" (Smith-Davis \& Billingsley, 1993, p. 205). This interaction occurs at the local, state, and national levels, and opportunities and responsibilities to address demand-supply imbalances occur at all three levels. With a focus on teacher quality and quantity at the national level, the purpose of this research is to portray and interpret long-term trends in the demand, supply, and shortage of special education teachers (SETs) for 16 school years, from 1987/1988 through 2002/2003.

The total national demand for teachers in public education is commonly defined as the number of teaching positions that have been established and funded, while the total supply of teachers is defined as the number of eligible individuals available from all sources who are willing to supply their services under prevailing conditions (Boe \& Gilford, 1992; see Note 1). Ideally, teacher demand is balanced by an adequate supply. Teacher shortages are, of course, the result of either exceptional high demand in relation to supply and/or exceptionally low supply in relation to demand. An inadequate supply of teachers in relation to demand inevitably results in a shortage.

It is widely recognized that there has long been an imbalance between the demand for SETs and the supply of SETs, thereby resulting in serious shortages (e.g., Smith-Davis \& Billingsley, 1993; Council for Exceptional Children, 2000; McLeskey, Tyler, \& Flippin, 2004; Boe \& Cook, 2006). However, analysis of teacher shortages requires a distinction between two types of demand and the adequacy of supply in relation to each type:

- Quantity demand-The demand for the number of teachers to fill all teaching positions that have been created and funded at the district level

- Quality demand-The demand for teachers with specific qualifications (e.g., certification, degree major field, and teaching experience) 
Unfortunately, the national quantity demand for SETs as defined above is not known precisely because current databases record the number of teachers employed, not the somewhat larger number of positions that have been established and funded. The difference between the number of filled positions and the number of positions that have been funded is the number of positions that are vacant.

For a period of 5 years in the 1990s (1993/1994 through the 1997/1998 school years), the Office of Special Education Programs (OSEP), of the U.S. Department of Education (USDE), provided information about the number of vacant teaching positions in special education in its annual reports to Congress on the implementation of the Individuals with Disabilities Education Act (IDEA) (OSEP, 1996, 1997, 1998, 1999, 2000). During this 5-year period, the median number of vacant full-time equivalent (FTE) teaching positions in special education was about 3,600 positions, or 1.1\% of total FTE positions (OSEP, 1996, 1997, 1998, 1999, 2000). These vacant positions can be construed as the "quantity shortage" of SETs (i.e., the number of positions for which there was an insufficient supply of eligible individuals who were available and willing to accept positions under the terms of appointment established by hiring school districts). Although the national quantity shortage percentage was small, the number of classrooms without a teacher was not trivial.

These OSEP data on vacant teaching positions in special education may be the most reliable because they are based on population data. Other information about vacant teaching positions is available from two national sample surveys. Based on data from its Schools and Staffing Survey (SASS) for 1993/1994, the National Center for Education Statistics (NCES) reported that only $0.2 \%$ of all teaching positions in public schools nationwide were unfilled (Henke et al., 1997). This percentage of vacant teaching positions for all teachers is much lower than the $1.1 \%$ reported for SETs during the mid-1990s in OSEP's (1996, 1997, 1998, 1999, 2000) annual reports to Congress on the implementation of IDEA. The Henke et al. report can be disregarded here because it did not break down the vacant positions in special education per se. More recently, a report based on a national survey entitled "Study of Personnel Needs in Special Education (SPeNSE)," conducted in 1999/2000 for OSEP (Carlson, Brauen, Klein, Schroll, \& Willig, 2002), stated that $2.9 \%$ of teaching positions in special education (12,241 positions) were either vacant or filled by substitute teachers. This percentage of teaching positions is much higher than the 1.1\% reported for SETs in the mid-1990s in OSEP's annual reports to Congress on the implementation of IDEA. The Carlson et al. report also can be disregarded here because it did not differentiate the vacant positions from the substitute teacher positions. Consequently, the percentage of vacant teaching positions in special education (1.1\%) reported by OSEP remains the best available estimate. Thus, the total demand for SETs (i.e., the number of teaching positions created and funded) can best be approximated by multiplying the number of filled positions by $101.1 \%$.

Regarding quality demand, all states in the U.S. require that teaching positions be filled with teachers who are fully certified in their position (National Association of State Directors of Teacher Education \& Certification, 2003; see Note 2). Accordingly, the quality demand for fully certified teachers is numerically the same as the quantity demand (i.e., the number of teaching positions that have been created and funded).

Based on OSEP data, McLeskey et al. (2004) reported that $11.4 \%$ of all SETs during the 2000/2001 school year lacked appropriate certification. This lack of certification can be construed as one index of the "quality shortage" of SETs. In 2000/2001, this shortage represented 47,532 positions filled by teachers without full certification (McLeskey et al.). The 
quality shortage of SETs was substantial (11.4\%), and over 10 times as great as the quantity shortage identified above.

Of course, the demand for qualified teachers involves much more than full certification per se. The No Child Left Behind Act of 2001 (NCLB) defined the concept of a "highly qualified teacher" and prescribed that all public school teachers of core subject matters be highly qualified by the end of the 2005/2006 school year (as cited in USDE, 2004b). NCLB defined a highly qualified teacher as one with(a) a bachelor's degree, (b) full certification, and (c) demonstrated expertise in the subject matter of each core subject taught. Thus, there is a federal statutory quality demand for teachers who attain all three qualifications. Since all teachers of core subjects are required to be highly qualified by NCLB, the size of the national quality demand (i.e., the demand for teachers with specific qualifications) for such teachers is the same as the quantity demand for such teachers. To the extent that the supply of qualified teachers does not satisfy the quality demand, there is a shortage of qualified teachers. This shortage, in turn, creates a quantity demand for the number of additional qualified teachers needed to satisfy the shortage.

There are two main sources of ongoing national data about the quantity and quality demand for SETs. The first is OSEP's Data Analysis System (DANS) (Westat, 1997). The second is the Schools and Staffing Survey (SASS) of the National Center for Education Statistics, USDE) (Tourkin, 2004). These two data sources are largely complementary; each has strengths and limitations for analyzing teacher supply, demand, and shortage in special education. DANS (but not SASS) provides information annually about the numbers and certification status of teachers for students with disabilities aged 3-5 years, and the numbers of students with disabilities aged 3-21 years. It also provides information annually about all SETs and all students with disabilities. Among many other aspects of the teaching force, SASS (but not DANS) provides information about the (a) sources of supply of SETs, (b) qualifications of SETs in addition to certification status (e.g., teacher preparation, degree level, experience), and (c) teachers in general education. In other respects, both DANS and SASS provide information about the quantity demand for SETs for students with disabilities aged 6-21 years and the shortage of fully certified SETs for such students.

Therefore, only data from DANS can be used to assess trends in (a) the demand for SETs in relation to the numbers of students with disabilities aged 3-21 years; (b) the demand and shortage of SETs for students with disabilities aged 3-5 years; and (c) differences in the demand, supply, and shortage of SETs for students with disabilities aged 3-5 years versus aged 6-21 years. Accordingly, this research capitalizes on the potential of DANS to provide unique insights into the supply, demand, and shortage of SETs. Other recent research with SASS capitalizes on its potential to provide such unique insights about SETs (e.g., Boe \& Cook, 2006; Cook \& Boe, in press).

One of the fundamental responsibilities of policymakers and administrators in education is to assure that all teaching positions in our nation's public schools are filled by qualified teachers the most basic dimension of which is that teachers be fully certified in their respective positions. In continuing efforts to fulfill this responsibility, policymakers and administrators in special education can benefit from basic information about the extent to which past initiatives have succeeded and/or failed - as quantified by sound data about teacher demand, supply, and shortage. The types of information about SETs that should be useful to policymakers and administrators to gain a better understanding of the problem of increasing teacher demand and shortages include (a) trends over time in the growth of demand for SETs, (b) trends over time in 
the supply and shortages of SETs, (c) relationships over time between growth in the number of students with disabilities and growth in the demand for SETs, (d) differences in the demand and shortage of SETs as a function of the level of students served, (e) differences in the demand and shortage of SETs as a function of specialization within special education, and (f) trends over time in the growth of demand for SETs in comparison with general education teachers (GETs). Long-term trend data about these and other important aspects of the supply, demand, and shortage of SETs are produced annually by DANS (except for teachers subdivided by specialization) and are published in OSEP's annual reports to Congress on the implementation of IDEA (e.g., 1998). In this form, however, neither year-to-year changes nor long-term trends in the teaching force in special education are readily accessible to policymakers, administrators, and researchers. Accordingly, the purposes of this research are to organize, analyze, and present data from DANS in a series of eight figures that portray trends in the supply, demand, and shortage of SETs during 16 school years (1987/1988 through 2002/2003). Dissemination of DANS information in this form should enhance its value to those responsible for assuring that a qualified teaching force exists in special education. To accomplish this purpose, we extended annual trend data published in OSEP's 20th Annual Report to Congress on the Implementation of the Individuals with Disabilities Education Act (1998, Section III) for 9 school years (1987/1988 through 1995/1996) an additional 7 years (through school year 2002/2003).

\section{Method}

\section{Data Source}

Trends in the demand, supply, and shortage of special education teachers were based on OSEP's annual reports to Congress on the implementation of IDEA from 1990 (OSEP, 1990, reporting data for the 1987/1988 school year) through 2005 (OSEP, in press, reporting data for the 2002/2003 school year). I chose school year 1987/1988 as the base year because it was the first year for which data were reported separately for teachers serving students with disabilities aged 3-5 years and for teachers serving students with disabilities aged 6-21 years. School year 2002/2003 is the last year for which data are currently available. The source of these data were OSEP's DANS for the U.S. and Outlying Areas. This system contains national population data on special education students and teachers (counted in FTE units) that have been reported to OSEP by all states and outlying areas. DANS records the total number of SETs, subdivided into those who are fully certified in their main teaching assignment and those who are not fully certified. Fully certified SETs (including long-term substitutes) hold standard (or higher) certification or licensure (in the state in which they are employed) for the teaching position to which they are assigned. SETs not fully certified for the teaching position to which they are assigned may hold emergency, provisional, or other certification, or may be uncertified. Thus, SETs classified as not fully certified represent a range of qualifications less than full certification.

During the 16 years for which data were abstracted and analyzed for this report (school years 1987/1988 to 2002/2003), the definitions of teacher categories used by DANS to collect and organize information were stable, except for reporting of vacant teaching positions - a component of the total demand for SETs. For data from school years 1987/1988 through 1992/1993, the reporting of vacant teaching positions was combined with positions filled by teachers who were not fully certified. For 5 years - from 1993/1994 through 1997/1998 - the number of vacant positions was reported along with the number of not fully certified teachers. Since 1997/1998, however, reporting of the number of vacant positions was discontinued. 
Instead, only the number of positions filled with fully certified and with not fully certified teachers has been reported.

Even though DANS provides information for the population of SETs in the nation, it is subject to various errors, such as the accuracy of reporting and tabulation. Therefore, no particular data point for one year should be interpreted as error free. Instead, consistent data over more than one year provide the most reliable information about a variable of interest.

\section{Analysis Procedures}

Annual data from DANS for a 16-year period were organized, analyzed, and presented in four types of figures:

a. Numbers of teachers-This procedure provides information about growth over time in the absolute number of employed SETs.

b. Cumulative percent growth of students and teachers-This procedure provides information about percentage increases over time in the numbers of students with disabilities and in the numbers of teachers relative to a baseline year (1987/1988), cumulated year by year. Accordingly, rates of growth in the numbers of students and teachers can be compared on a common metric (i.e., percentage of growth over a baseline year).

c. Percentages of not fully certified teachers - This procedure provides information about changes over time in the shortage of fully certified teachers as a percentage of total teachers. Accordingly, teacher shortage percentages for two student age groups can be compared on a common metric.

d. Ratio of students to teachers - This procedure provides information about changes over time in the number of students per teacher. Accordingly, student-teacher ratios for two student age groups can be compared on a common metric.

\section{Results}

\section{Trends in the Demand and Supply of Teachers for Students Ages 3-5 Years With Disabilities}

Dramatic growth in the total demand for SETs (i.e., the number of teaching positions nationally) for students aged 3-5 years is shown in Figure 1. From 1987/1988 to 1999/2000, demand increased by $140 \%$, from about 12,700 to about 30,500 teachers.

There was an even greater percentage increase (166\%) in the supply of fully certified teachers in response to this demand. These trends demonstrate that the field of special education was remarkably successful through 1999/2000 in meeting the rapidly increasing demand for teachers of students aged 3-5 years. 


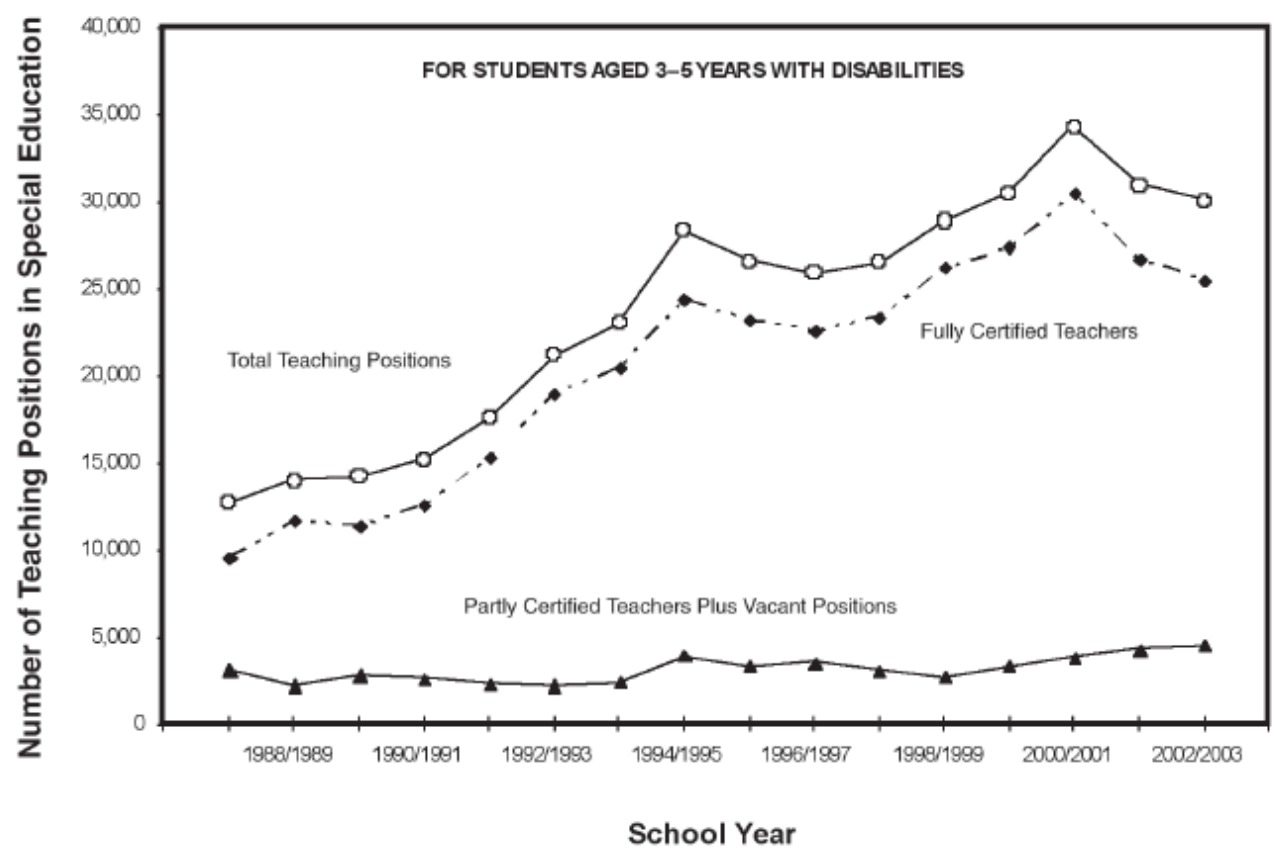

FIGURE 1. Number of full-time equivalent teaching positions in special education in the U.S. and outlying areas for students aged 3-5 years with disabilities, broken down by the number of fully certified teachers and the sum of not fully certified teachers plus vacant teaching positions (through 1997/1998), by school year (based on the Data Analysis System of the Office of Special Education Programs, U.S. Department of Education).

After 13 years (1987/1988 through 1999/2000) of growth in SET demand for students aged 3-5 years, demand appears to have stabilized during the following 3 years on the whole. Little or no significance should be placed in the apparent sharp increase in teacher demand shown for $2000 / 2001$ because it is out of line with the percentages in the immediately preceding, and following, years (and probably entails an unusual amount of reporting error).

Using school year 1987/1988 as the baseline, Figure 2 shows the cumulative percentage increase during the following 15 years in the number of students with disabilities aged 3-5 years and their teachers. As seen in Figure 2, the number of SETs for students aged 3-5 years grew at a higher rate over the 16-year period (137\%) than did the number of students they taught (growth of 102\%). Thus, the student-teacher ratio necessarily declined modestly from 26.5:1 in 1987/1988 to 22.6:1 in 2002/2003 — a condition generally welcomed by teachers and thought to foster enhanced student learning (see Note 3).

\section{Trends in the Demand and Supply of Teachers for Students Ages 6-21 Years With Disabilities}

In contrast with the rapid growth in SET demand for students aged 3-5 years with disabilities, a gradual growth occurred in the number of total teaching positions nationally for students aged 621 years, as shown in Figure 3. From 1987/1988 to $2002 / 2003$, demand increased by $42 \%$, from about 284,300 to about 403,100 teachers. (If an adjustment were made for an estimated $1.1 \%$ of vacant positions in 2002/2003, the total demand would be 407,500.) There was a lesser, but still noteworthy, increase of 37\%, from 257,700 to 353,300 , in the supply of fully certified teachers in response to this demand. On the positive side, these trends demonstrate that the field of special education was successful in increasing the 
supply of fully certified employed teachers of students aged 6-21 years by about 95,000 during the 16-year period analyzed here. On the negative side, this level of growth in fully certified teachers was well below the demand, as 49,700 employed teachers in 2002/2003 were not fully certified.

Using school year 1987/1988 as the baseline, Figure 4 shows the cumulative percentage increase during the following 15 years in the number of students with disabilities aged 6-21 years and their teachers. As seen in Figure 4, the number of students aged 6-21 years grew at a steady rate over the 16-year period, while the rate of growth in the number of their teachers mostly lagged behind during the last 9 years examined. Thus, the field of special education has not been able over time to either (a) increase the number of teaching positions in proportion to the growth of students or (b) maintain the percentage of fully certified employed teachers. Considered in isolation from other possible changes in the field, neither of these circumstances bodes well for the instruction of students with disabilities aged 6-21 years.

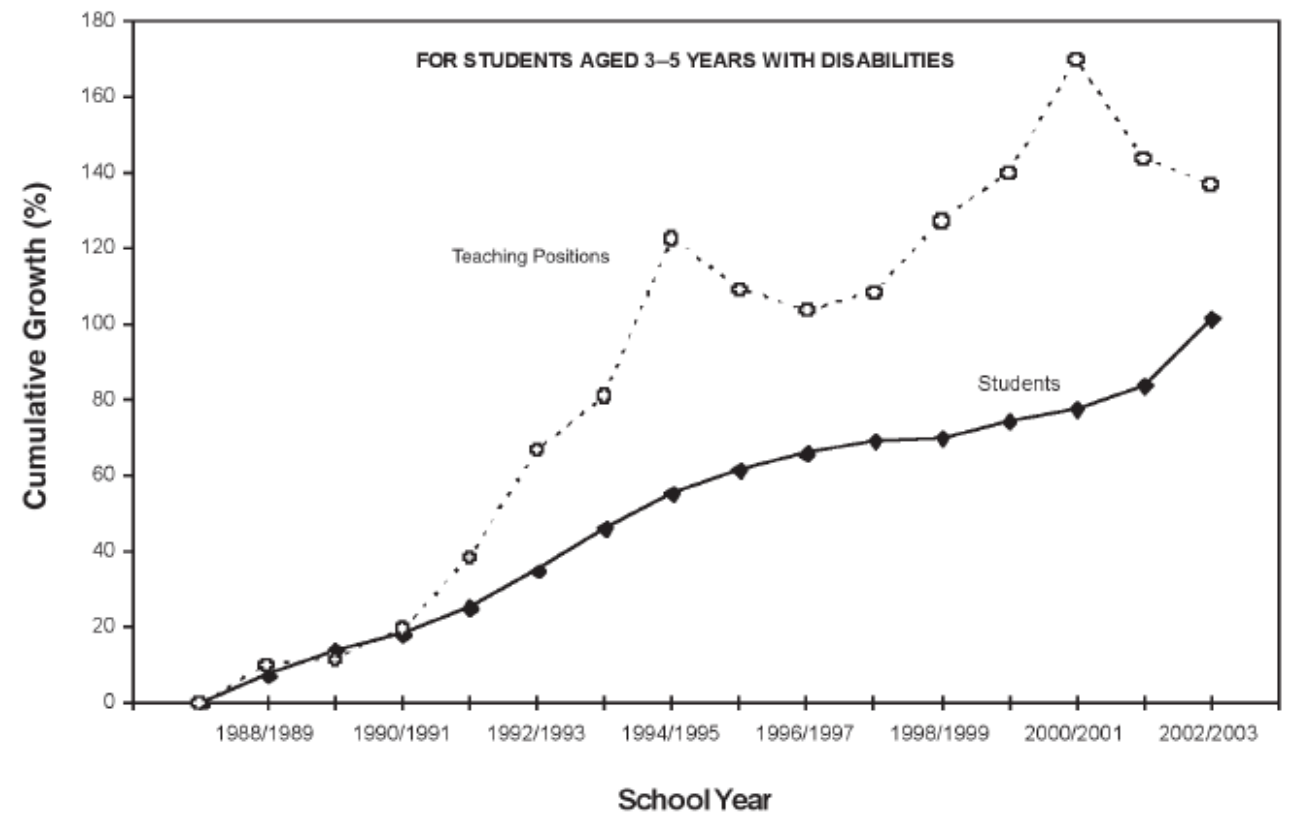

FIGURE 2. Cumulative percentage of annual growth in the number of students aged $3-5$ years with disabilities, compared with the cumulative percentage of annual expansion of full-time equivalent teaching positions in special education for these students, by school year (based on the Data Analysis System of the Office of Special Education Programs, U.S. Department of Education). 


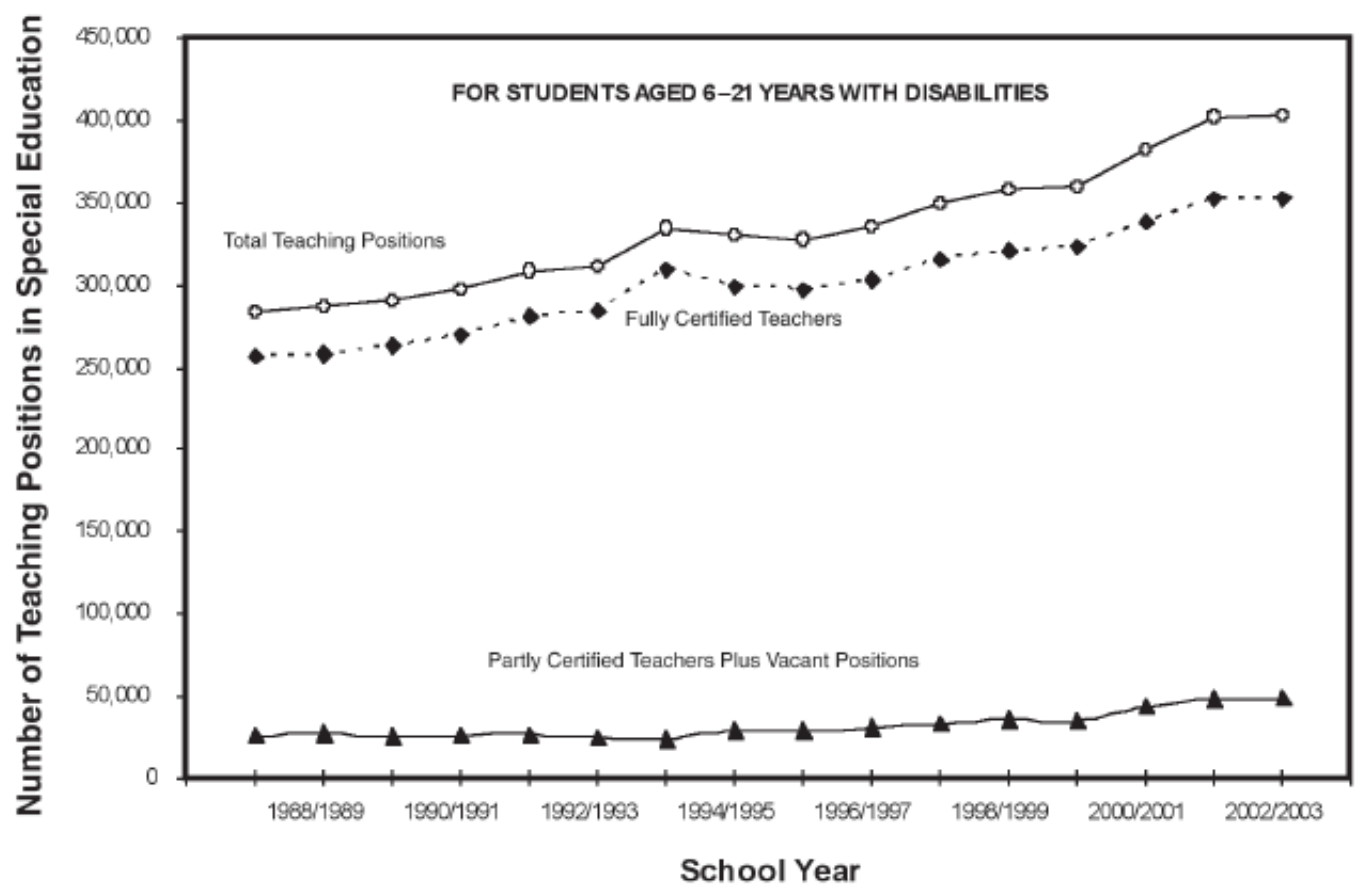

FIGURE 3. Number of full-time equivalent teaching positions in special education in the U.S. and outlying areas for students aged 6-21 years with disabilities, broken down by the number of fully certified teachers and the sum of not fully certified teachers plus vacant teaching positions (through 1997/1998), by school year (based on the Data Analysis System of the Office of Special Education Programs, U.S. Department of Education).

\section{Trends in Teacher Shortage}

In contrast with Figures 1 and 3, which presented trends in the numbers of teachers that were not fully certified combined with vacant positions (the latter through 1997/1998), Figure 5 presents these shortages as percentages of total teacher demand. These percentages are a measure of the teacher quality shortage (in terms of not fully certified teachers) for students with disabilities, presented separately for aged 3-5 and 6-21 years.

As seen in Figure 5, the percentage shortage of fully certified teachers for students aged 3-5 years declined substantially by 1998/1999 to a level equivalent to the shortage of fully certified teachers for students aged 6-21 years (the 10\% level). Since that time, the shortage of fully certified teachers for students aged 3-5 years increased more rapidly than the increase in teacher shortage for students aged 6-21 years. By 2002/2003, the shortage of teachers for students aged 3-5 years (15\%, representing 4,500 teachers) exceeded the level seen in 1991/1992 (13\% shortage, representing 3,100 teachers. Nonetheless, the field of special education reduced the shortage percentage of fully certified teachers for these students from the higher levels seen during the 4-year period from 1987/1988 through 1990/1991. Given the recent trend toward increasing shortage percentages, it is questionable whether these gains can be sustained. 


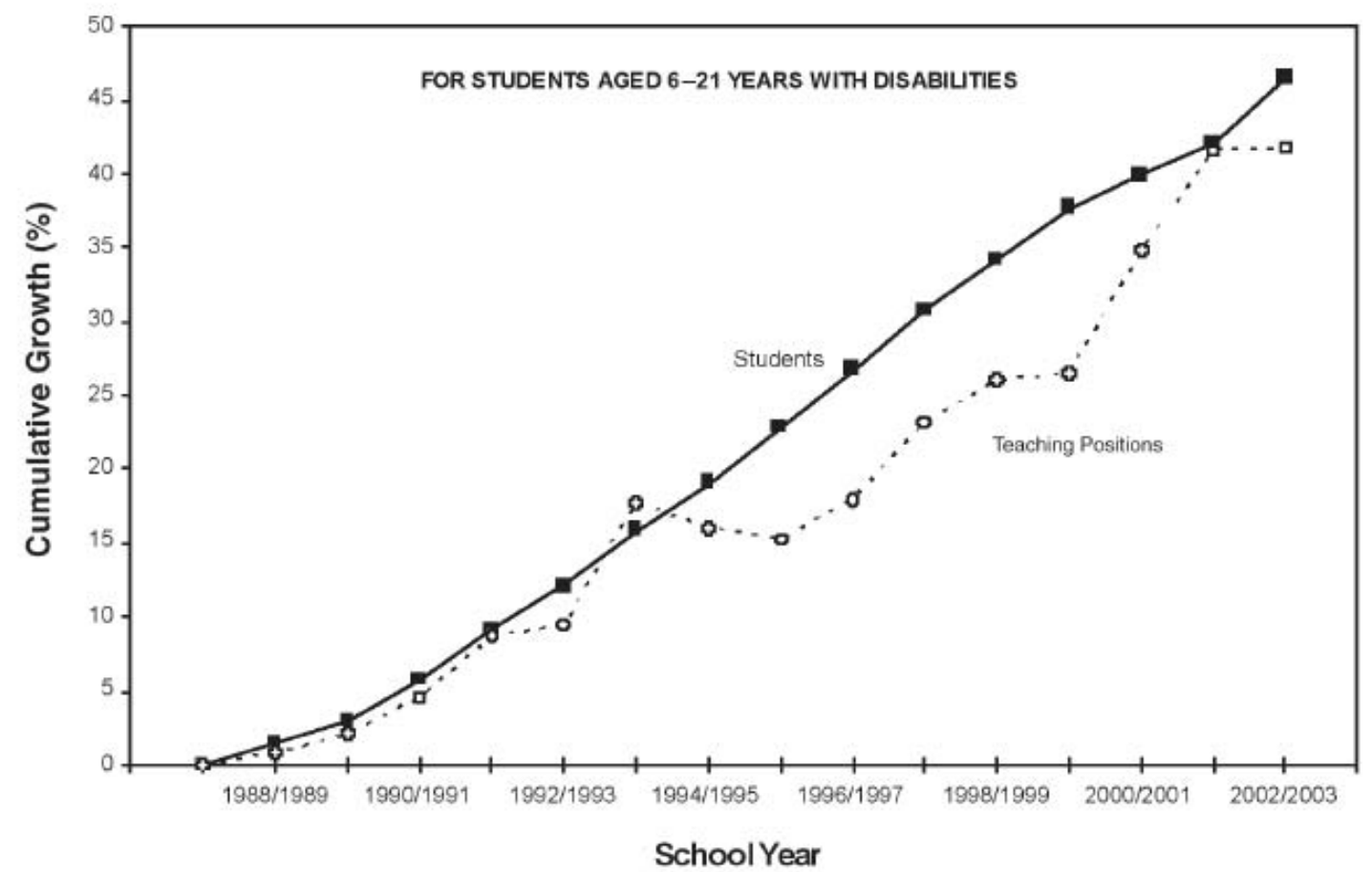

FIGURE 4. Cumulative percentage of annual growth in the number of students aged 6-21 years with disabilities, compared with the cumulative percentage of annual expansion of full-time equivalent teaching positions in special education for these students, by school year (based on the Data Analysis System of the Office of Special Education Programs, U.S. Department of Education).

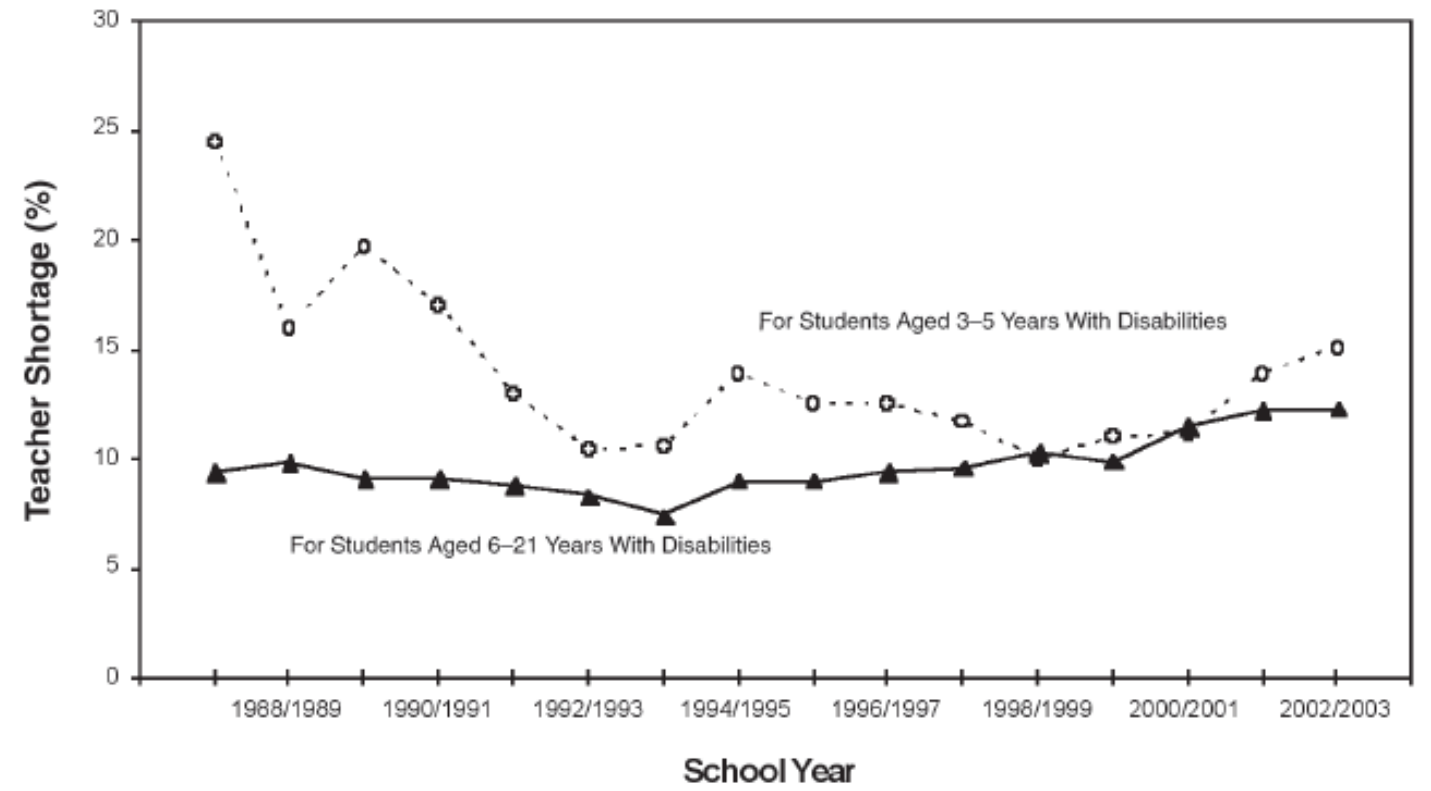

FIGURE 5. Teacher shortage percentages for students aged 3-5 years and 6-21 years with disabilities by school year (based on the Data Analysis System of the Office of Special Education Programs, U.S. Department of Education). Shortage is defined as the percentages of full-time equivalent teaching positions in special education that were (a) filled by teachers who were not fully certified for the position to which they were assigned and (b) were vacant through 1997/1998. 
In spite of the gradual growth in SET demand for students aged 6-21 years, the shortage of fully certified teachers decreased somewhat, from 9.4\% in 1987/1988 to 7.4\%, in 1993/1994 (Figure 5). Since 1993/1994, however, the shortage percentage has increased steadily. In addition, since 1997/1998, 1.1\% should be added to the shortage percentages to account for estimated vacant positions. Including estimated vacant positions, the shortage of fully certified teachers for students aged 6-21 years by 2002/2003 was 13.4\% (about 54,200 teachers). This finding defines the quality shortage of SETs (in terms of full certification) for students aged 6-21 years and demonstrates that the field of special education has been unable to keep up with the long-term increasing demand for fully certified teachers.

In addition to the need to upgrade or replace the 49,700 employed SETs who were not fully certified in 2002/2003, there is an annual national demand for about 26,000 entering teacher hires in special education for students aged 6-21 years (Cook \& Boe, in press) —all of whom should be fully certified in their main teaching assignment. However, the annual national production in 2001 of degree graduates with a major in special education instruction was only about 20,000 at the bachelor's and master's degree levels combined (see Note 4). Of these, almost half had already been employed as teachers at the time of graduation (Cook \& Boe). Thus, new graduates in special education instruction are far from sufficient in numbers to fill open positions for entering teachers or to replace employed SETs who are not fully certified. Neither is the reserve pool (the other source of supply of entering teachers) sufficient for this purpose. These shortfalls in teacher supply represent a major reason why the shortage of fully certified SETs has been chronic during the 16 years studied here. The magnitude of the chronic shortage of fully certified SETs for students aged 6-21 years with disabilities can also be viewed by contrasting the shortage of SETs with that of GETs. Available evidence suggests that, for students in grades $\mathrm{K}-12$, the shortage of fully certified GETs stood at $10.5 \%$ (based on 1999/2000 SASS data), whereas the comparable shortage of SETs stood at $13.7 \%$ (also based on 1999/2000 SASS data, adjusted upward by $1.1 \%$ to account for vacant positions (Boe \& Cook, 2006).

\section{Trends in Student-Teacher Ratios}

Teacher shortages might be explained, at least in part, by policies designed to reduce the ratio of students per teacher. Such reduction would require a greater rate of increase in the number of teachers than the rate of increase in the number of students. Although the number of SETs for students aged 3-5 and 6-21 years increased substantially during the years following 1990/1991 (as shown in Figures 1 and 3), the rate of growth in the number of SETs for students aged 3-5 years was much greater than for students aged 6-21 years, as the trends in Figure 6 demonstrate.

The relationship between growth in the number of SETs and growth in the number of students with disabilities is shown in Figure 7 in terms of trends in the student-teacher ratio for each of two student age groups. Specifically, the number of students per teaching position for the 3-5 age group declined from a ratio of 27.2:1 in 1989/1990 to a ratio of 17.5:1 in 2000/2001 (before increasing to 22.6:1 2 years later). In contrast, the comparable ratio for the 6-21 age group held remarkably steady, at close to 15:1 throughout the 15-year period studied. Thus, the shortage of SETs for students aged 3-5 years with disabilities might be explained, in part, by efforts to rapidly reduce the student-teacher ratio, thereby putting extraordinary pressure on sources of supply. But the same explanation does not apply to the shortage of SETs for students aged 6-21 years, since the student-teacher ratio was stable, at approximately 15:1, during the 15-year period examined. 


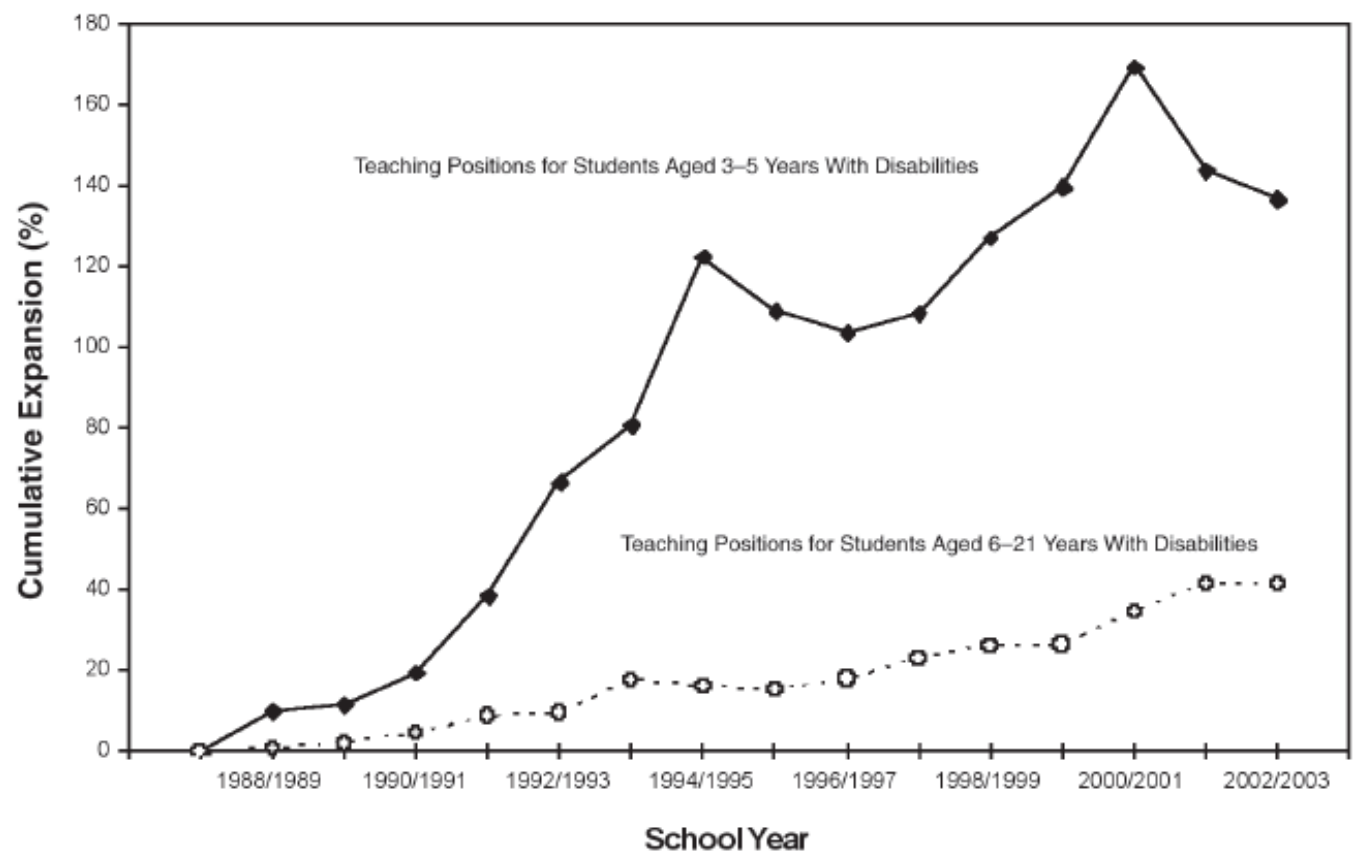

FIGURE 6. Cumulative percentage of annual expansion of full-time equivalent teaching positions in special education for students aged $3-5$ years and 6-21 years with disabilities by school year (based on the Data Analysis System of the Office of Special Education Programs, U.S. Department of Education).

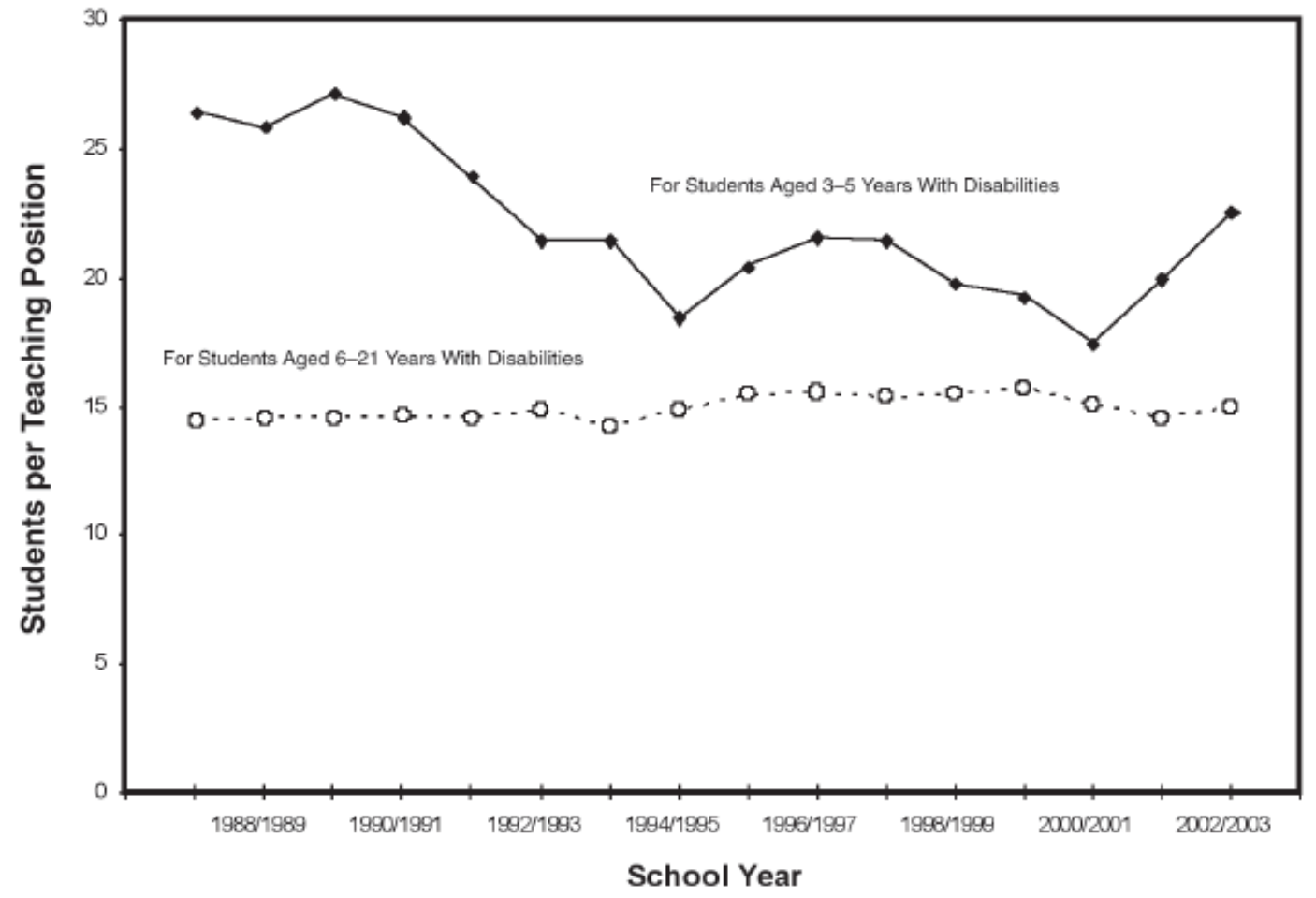

FIGURE 7. Students per teaching position by student age group and school year: Number of students with disabilities, divided by the number of full-time equivalent teaching positions in special education in the U.S. and outlying areas (based on the Data Analysis System of the Office of Special Education Programs, U.S. Department of Education). 
The trends in Figures 6 and 7 clearly suggest a long-term policy from 1989/1990 to 2000/2001 to accelerate the growth of SET positions for students aged 3-5 years to bring the ratio of students per teaching position for this age group more in line with that for students aged 6-21 years. Why this trend would seem to reverse in the 2 years following 2000/2001 is not clear from these data, but it may be due (at least in part) to a particularly rapid increase in students aged 3-5 years from 2000/2001 to 2002/2003 (a 2-year increase of about 80,000 students, as shown in Figure 2, representing an increase of over 13\%). Whereas a substantial increase in the supply of teachers was needed to maintain or improve the ratio of students to teachers, the number of SETs did not increase from the years 1999/2000 to 2002/2003 (as discussed above with respect to Figure 1).

\section{Trends in the Demand for Teachers in Special and General Education}

The chronic and increasing shortage of fully certified SETs for students aged 6-21 years with disabilities (as seen in Figure 5) might be explained, at least in part, by a rate of growth in teaching positions in special education that was much higher than in general education. If so, extraordinary increases in teacher demand in special education could more rapidly drain multiple sources of supply (such as the reserve pool) of qualified teachers. Evidence of the relative rates of expansion of teaching positions in special education (for students aged 6-21 years) versus general education (for students in grades $\mathrm{K}-12$ ) is presented in Figure 8 for the 16-year period of this study (see Note 5). It appears that teaching positions in both special and general education expanded by similar percentages during the first 14 years of this period (27.7\% for general education; 26.53\% for special education). As happened in the first half of the 1990s, however, the expansion of teaching positions in special education increased at a higher rate during the 2 years following 1999/2000. This expansion of teaching positions was most likely necessary to help catch up with earlier increases in the numbers of students aged 6-21 years (as seen in Figure 4). During the 10-year period from 1993/1994 to 2002/2003, the number of students aged 6-21 years with disabilities increased by $26 \%$, while the number of their teachers increased by only $20 \%$.

Since the teaching positions in special education and in general education expanded by comparable percentages through 1999/2000, the shortage of teachers in special education cannot be attributed to extraordinarily rapid expansion of teaching positions (i.e., demand) in contrast with general education. Instead, other evidence suggests that various sources of teacher supply were inadequate to satisfy the demand of fully certified SETs (e.g., Cook \& Boe, in press). 


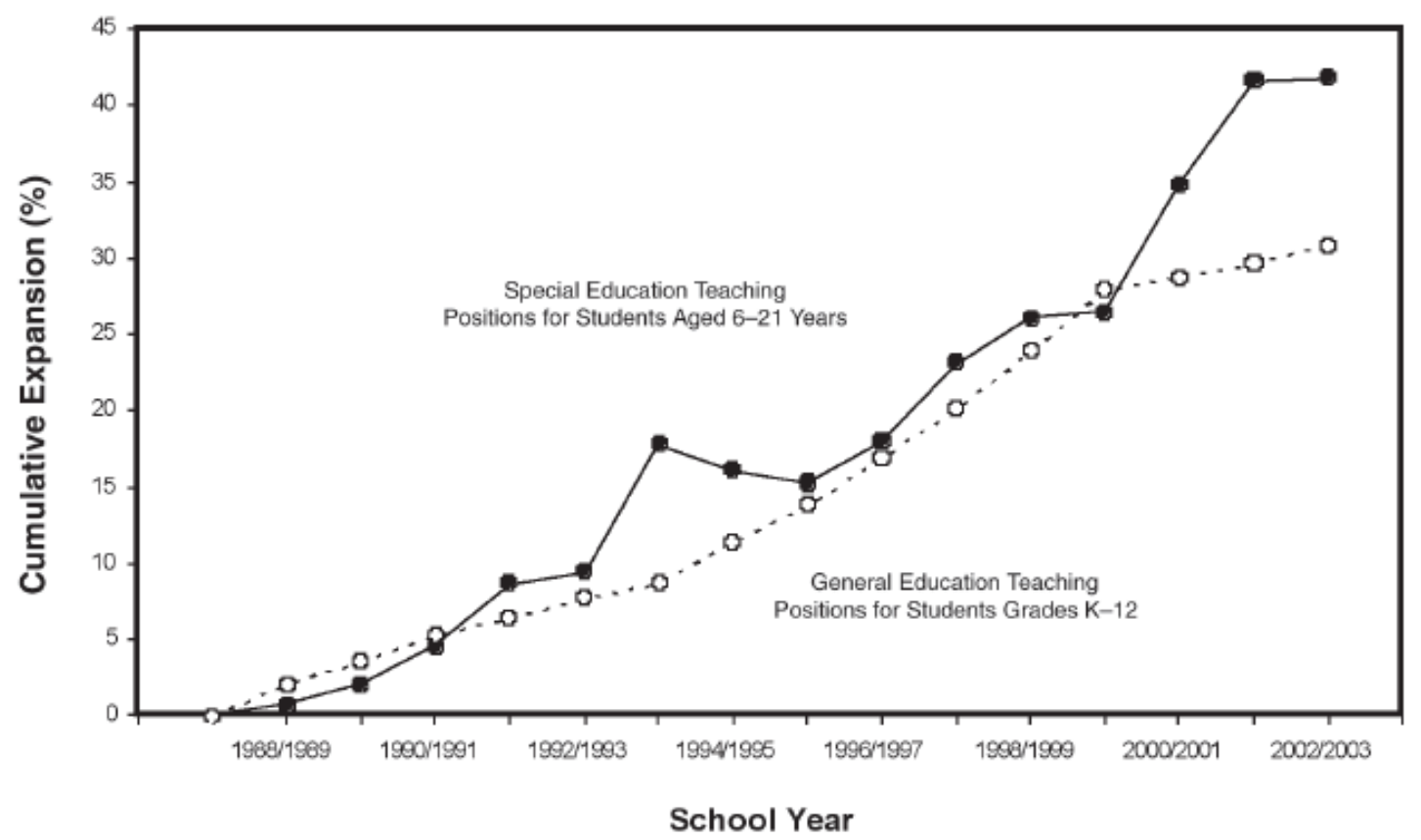

FIGURE 8. Cumulative percentage of annual expansion of full-time equivalent teaching positions in special education (for students aged 6-21 years with disabilities) and general education (for grades K-12 in public schools) by school year (based on the Data Analysis System of the Office of Special Education Programs, U.S. Department of Education, and the Common Core of Data of the National Center for Education Statistics, U.S. Department of Education).

\section{Discussion}

Steady increases over time in the number of students with disabilities (both aged 3-5 years and 6-21 years) have been associated with increases in the numbers of teaching positions, mostly filled with fully certified teachers. This represents a remarkable achievement by teacher preparation and professional development programs in special education to increase the supply of fully certified SETs. Nonetheless, the unmet demand for fully certified teachers also grew substantially. This represents a failure to satisfy the quality demand for a fully and appropriately certified teacher in every special education classroom.

During the two most recent school years (2001/2002 and 2002/2003), three indicators demonstrate serious reversals in the teaching force for students aged 3-5 years with disabilities: (a) the number of teaching positions may have started to decline in spite of continued growth in the number of students, (b) the percentage of not fully certified teachers (i.e., the shortage) increased sharply, and (c) the ratio of students to teachers began to increase. These reversals occurred in spite of gradual and considerable improvement in these indicators during prior years. Further research is needed to explain why these indicators of the teaching force for students aged $3-5$ years have deteriorated recently.

The trends in teachers for students aged 6-21 years with disabilities differed in important ways from those for students aged $3-5$ years. The rate of growth in teaching positions has approximated the rate of growth in the number of students served. Since 1993/1994, however, the shortage percentage of fully certified SETs for students aged 6-21 years increased 
substantially during the following 10-year period, to 13.4\% (54,200 teaching positions, including estimated vacant positions). This phenomenon has been described as the chronic and increasing shortage of SETs (Boe \& Cook, 2006), and represents a major challenge to the field in generating an adequate supply of fully certified SETs in response to the demand. This shortage percentage (13.4\%) compares unfavorably with that in general education (10.5\%), especially because rate of growth in teaching positions to be filled has been comparable in special education and in general education.

The increasing shortage of fully certified SETs represents a major challenge for policy and practice in special education relevant to developing and sustaining a qualified teaching force the clear implication of which is that the field of special education should devote even more attention and resources to solve its teacher shortage problem. Although the trends in teacher demand, supply, and shortage examined in this study do not provide information specifically about which of many policies and practices should be used to address these shortages, the trends represent hard evidence that the problem is serious and has gradually worsened during recent years.

Two broad approaches are relevant to addressing the shortage of over 54,000 fully certified SETs for students aged 6-21 years with disabilities. One approach is to reduce teacher demand; the other is to increase teacher supply. Four possible strategies to reduce demand are considered below: (a) improve retention of qualified SETs through reduced exit attrition and transfer to general education; (b) redesign the education process, such as by using technology or teacher aids more extensively, so that fewer SETs are needed; (c) reduce the number of students classified with disabilities; and (d) increase the proportion of instruction provided by GETs for students with disabilities (i.e., increase inclusion practices). In spite of advocacy for improved retention of teachers (e.g., National Commission on Teaching and America's Future, 2003), annual attrition rates of teachers are no higher (and may well be lower) than such rates in other vocations (Boe, Cook, \& Sunderland, 2005). Thus, leaving employment in a vocation is a common phenomenon, and the teaching profession is not disadvantaged in this respect. Of SETs who do leave teaching, only $37 \%$ do so to escape (i.e., actively want to leave for better jobs, etc.). Most leavers do so for personal reasons or to retire (Boe et al.). Thus, well under half (about 7,000) of the approximately 20,000 SET leavers per year may potentially be affected by policy initiatives intended to improve retention. If effective actions could be taken to make special education teaching sufficiently attractive to reduce escape leaving by half, then 3,500 of these would remain, thereby reducing the demand for about 54,200 fully certified SETs in $2002 / 2003$ by $6 \%$. While this would not be trivial if all those retained were fully certified, other strong actions would also be needed to upgrade or to replace the remaining 50,700 SETs who are not fully certified.

With respect to SETs who transfer to general education each year, there is an equivalent gain from GETs who transfer to special education. In addition, there is neither gain, nor loss, in the qualifications of teachers who transfer out of, and into, special education (Boe et al., 2005). Furthermore, many SETs probably wish to transfer to general education because it is the field of their preparation. Approximately one in five first-time SETs earned a major in an area of general education teacher preparation (Cook \& Boe, in press). With 33,000 SETs transferring to general education following the 1999/2000 school year, it is important to understand better the reasons why so many either chose to transfer or were reassigned by administrative action.

Perhaps there is considerable potential for increased retention of SETs (i.e., both reduced numbers of SETs who leave to escape teaching and who switch to general education) through 
improved induction, professional development, and working conditions (Billingsley, 2005), but the effectiveness of interventions should be tested in the field. In addition, more needs to be known about the qualifications of SETs who escape from teaching and who transfer to general education. Preliminary evidence indicates that many are not highly qualified (Boe et al., 2005) and therefore should not be retained in their positions unless their qualifications are upgraded.

Turning to other possible interventions for reducing the demand for fully certified SETs, little reduction may be expected through redesign of education processes or reduction in the number of students classified with disabilities. Radical change in one or both of these interventions would be needed to reduce teacher demand substantially, but it is as unlikely in the near future, as it has been in the past. Incremental steps along these lines would reduce teacher demand only marginally. However, the Response to Intervention (RTI) initiative is a newly identified process described in the 2004 reauthorization of IDEA for identifying students with learning disabilities (as cited in National Association of State Directors of Special Education, 2005). This initiative holds promise for substantially reducing the number of students eligible for special education services (and therefore also reducing the demand for SETs) if it proves to be effective and can be scaled up nationally.

In 1998, OSEP hypothesized that the downturn in demand for teachers of students aged 6-21 years observed during 1994/1995 and 1995/1996 "could be explained by increasing inclusion of students with disabilities into general education classrooms” (p. III-8). However, this downturn in demand reversed the following year, and the demand for SETs has since increased at a pace equivalent to that of increases in the number of students with disabilities.

Nonetheless, there has been a substantial increase in the inclusion of students with disabilities in general education classrooms during the period of 16 years examined in this study. As of 1987/1988, 28.9\% of students aged 6-21 years were served outside the regular classroom less than 21\% of the school day (OSEP, 2001, Table III-1). By 2002/2003, this percentage had increased substantially, to 48.2\% (OSEP, 2005). The change in these percentages represent a $67 \%$ increase in this index of inclusion during the 16-year period-a number well in excess of the $42 \%$ increase in demand for teachers during the same period of time. Nevertheless, the substantial gains made in inclusion were not associated with reduced demand for SETs, a demand that grew in proportion to increases in the numbers of students with disabilities. In the absence of a control condition, it is not possible to determine whether the demand for SETs may have grown even more had it not been for gains in inclusion. However, it is surprising that increasing inclusion was not associated with declining demand for SETs. The impact of inclusion on the demand for SETs is a prime topic for research.

Even if some reduction in demand for fully certified SETs is achieved, there is little reason to expect that the need for a much larger supply will be offset substantially in the future. Therefore, enlarged teacher supply is needed to address the chronic and increasing shortage of over 50,000 fully certified SETs for students aged 6-21. Four possible strategies to increase supply are considered below: (a) increased transfer of qualified GETs to teaching positions in special education, (b) improved recruitment of qualified teachers entering from the reserve pool, (c) expansion of initiatives to upgrade the qualifications of unqualified employed SETs, and (d) expansion of teacher preparation programs in special education to increase the production of novice teachers.

Little is known about the potential for increased transfer of GETs who are qualified for teaching in special education. There may be little potential for enhanced recruitment because an already 
large number of GETs transfer to special education. During the 1990s, approximately 25,000 GETs were recruited on an annual average basis into special education teaching positions, 22,000 of whom were fully certified in the positions to which they transferred (Boe et al., 2005). This was not a net gain for special education, however, because it merely offset an equivalent loss of fully certified SETs to general education. More research is needed to examine the potential of cross-field teacher transfers for enhancing the supply of qualified SETs, and the effectiveness of actions that might be taken to make teaching in special education more attractive to GETs who are qualified to teach in special education.

With respect to reentering experienced teachers (the major component of the reserve pool), OSEP (1998) concluded that this source of entering teacher supply was rapidly becoming depleted (p. III-17). Fortunately, this did not occur, as 42\% of all entering SETs in 1999/2000 had prior teaching experience (up from 33\% in 1993/1994;Cook \& Boe, in press). This percentage was virtually the same as the recruitment of reentering experienced teachers to general education. Overall, special education was as successful as general education in recruiting entering teachers from various sources of supply (Cook \& Boe). Accordingly, enhancing the supply of SETs by an even higher level of recruitment from the reserve pool will probably be quite difficult without the creation of greater incentives to enter special education teaching instead of general education. As is well known, the teaching profession has been resistant to creating strong incentives (e.g., a different pay scale) to attract teachers to high-shortage areas (either by subject matter or by school location).

In contrast, upgrading the qualifications of employed SETs represents a more promising approach to increasing the supply of qualified teachers. Almost 50,000 employed SETs nationally have not earned full certification in their main teaching assignment (OSEP, in press). However, they have demonstrated that they are able and willing to be employed in special education. Therefore, these teachers can be viewed, for the most part, as an asset worthy of further investment in upgrading their qualifications. This can be implemented by local education agencies encouraging, supporting, and providing incentives for such teachers to complete alternative routes to certification (ARC) or to enroll part-time in traditional teacher preparation programs at local colleges and universities. Certainly many SETs improve their qualifications from year to year through these means, but nothing is known from national research about the extent to which teacher preparation programs are used for this purpose. Consequently, research is needed on the extent to which such programs upgrade the qualifications of employed SETs annually, and the potential benefits of their expansion.

The fourth approach to enlarging the supply of qualified SETs is to expand the production of novice teachers for special education (both by traditional and alternative routes to teacher preparation and certification). Although ARC for special education have been proliferating nationally in recent years, little is known in the aggregate about the number of completers produced annually or about their effectiveness as teachers (Rosenberg \& Sindelar, 2005). Nonetheless, it is likely that ARC programs will produce increasing numbers of completers because it is the policy of the USDE to encourage and support their development in order "to move candidates into the classroom on a fast-track basis” (USDE, 2002, p. 15).

Even though the former Secretary of Education, Rod Paige, recognized that traditional teacher preparation programs "will always produce a large percentage of our teachers" (as cited in USDE, 2004a, p. v), federal encouragement and support has not been devoted to expansion of traditional university-based preparation leading both to degrees and teacher certification. The need for increased production of graduates by teacher preparation programs in special education 
has continued since OSEP's (1998, Section III) review of options because the demand for SETs has steadily increased. This increased demand has occurred even though the production of graduates by traditional teacher preparation programs in special education has increased from 1991 through 1998, while the production of programs in general education has remained stable (Cook \& Boe, in press). Nonetheless, the production of teacher preparation programs in special education was still not enough to satisfy the demand for fully certified SETs. Regrettably, the production of new graduates (at both the bachelor's and master's degree levels) has gradually declined since 1998 (Cook \& Boe). In the absence of federal initiatives, the responsibility for reversing this trend, and for further expanding the production of degree graduates in special education teaching, will continue to reside with the states in their support of teacher education programs in colleges and universities. Unless the decline in the production of graduates from teacher preparation programs in special education is not only reversed, but increased substantially, it is likely that the shortage of qualified SETs will continue to increase, not only in numbers, but also as a percentage of the teaching force in special education.

None of the strategies for reducing the demand for, or increasing the supply of, qualified SETs will be easy, or surely such actions would already have been taken. The shortage of sufficient numbers of qualified SETs to serve students with disabilities has been an intractable problem for decades that will require concerted effort and substantial resources to ameliorate. The field of special education has responded most dramatically in recent years by ramping up the production of teachers by alternative means. At the same time, however, the field has allowed the production of teachers by traditional means to decline. A similar ramping up of the production of teachers by traditional means would reduce the shortage substantially. Given what is known about difficulties in reducing the demand for qualified SETs, strategies to increase their supply would seem to hold more promise for enhancing the qualifications of teachers in special education.

\section{NOTES}

1. Demand thus defined is also be referred to as the "total demand" for teachers to distinguish it from the "annual demand" for individuals to be hired as newly employed teachers each year to fill open positions. This distinction will be used later in this article.

2. Teacher certification is the most basic qualification established for teachers. While there are other important dimensions of teacher quality (Carlson, Lee, Schroll, Klein, \& Willing, 2002; Kennedy, 1992), the most readily available national information on the qualifications of SETs is their certification status for the positions to which they are assigned. For these reasons, only the certification dimension of teacher quality is considered here.

3. See Figure 7 for trends in student-teacher ratios during 16 years.

4. The annual demand for "entering teacher hires" refers to open teaching positions that are not filled by employed teachers who continue from one year to the next, even though many switch positions between school years. For example, thousands of general education teachers switch to special education each year to fill open positions. The remaining open positions in special education need to be filled by individuals entering the employed teaching force each year, thereby filling the annual demand for "entering teacher hires.”

5. To obtain the number of full-time equivalent teaching positions in general education, the number of full-time equivalent teaching positions in special education (as recorded by DANS) was subtracted from the number of full-time equivalent teaching positions in all teaching fields 
in Grades K-12, as recorded by the Common Core of Data of NCES (as cited in Snyder \& Hoffman, 2003).

\section{REFERENCES}

Billingsley, B. S. (2005). Cultivating and keeping committed special education teachers: What principals and district leaders can do. Thousand Oaks, CA: Corwin Press.

Boe, E. E., \& Cook, L. H. (2006). The chronic and increasing shortage of fully-certified teachers in special and general education. Exceptional Children. 72(4), 443-460.

Boe, E. E., Cook, L. H., \& Sunderland, R. J. (2005, July). Turnover of special education teachers: New research on the extent and impact of exit attrition, transfer to general education, and school transfer. Paper presented at the 2005 OSEP Project Directors Conference, Washington, DC.

Boe, E. E., \& Gilford, D. M. (1992). Summary of conference proceedings. In E. E. Boe \& D. M. Gilford (Eds.), Teacher supply, demand, and quality:Policy issues, models, and data bases (pp. 21-62). Washington, DC: National Academy Press.

Carlson, E., Brauen,M., Klein, S., Schroll, K., \& Willig,W. (2002). Key findings from the Study of Personnel Needs in Special Education. Washington, DC: Office of Special Education Programs, U.S. Department of Education.

Carlson, E., Lee, H., Schroll, K., Klein, S. Willing, S. (2002). Final Report of the Study of Personnel Needs in Special Education.Washington, DC: Office of Special Education Programs, U.S. Department of Education.

Cook, L. H., \& Boe, E. E. (in press). National trends in the sources of supply of teachers in special and general education (Research Report No. 2004-TSDQ1). Teacher Education and Special Education.

Council for Exceptional Children. (2000). Bright futures for exceptional learners. Reston, VA: Author.

Henke, R. R., Choy, S. P., Chen, X., Geis, S., Alt, M. N., \& Broughman, S. P. (1997). America's teachers: Profile of a profession, 1993-94.Washington, DC: National Center for Education Statistics, U.S. Department of Education.

Kennedy, M. (1992). The problem of improving teacher quality while balancing supply and demand. In E. E. Boe \& D. M. Gilford (Eds.), Teacher supply, demand, and quality: Policy issues, models and data bases (pp. 65-122). Washington, DC: National Academy Press.

McLeskey, J., Tyler, N. C., \& Flippin, S. S. (2004). The supply and demand for special education teachers: A review of research regarding the chronic shortage of special education teachers. The Journal of Special Education, 38(1), 5-21.

National Association of State Directors of Special Education. (2005). Response to intervention: Policy considerations and implementation. Alexandria,VA: Author. 
National Association of State Directors of Teacher Education \& Certification. (2003). The NASDTEC manual on the preparation and certification of educational personnel 2003 (8th ed.). Sacramento, CA: School Services of California.

National Commission on Teaching and America's Future. (2003). No dream denied: A Pledge to America's children. New York: Author.

Office of Special Education Programs (OSEP). (1990). Twelfth Annual Report to Congress on the Implementation of the Education of Handicapped Act. Washington, DC: U.S. Department of Education.

Office of Special Education Programs (OSEP). (1991). Thirteenth Annual Report to Congress on the Implementation of the Individuals with Disabilities Education Act. Washington, DC: U.S. Department of Education.

Office of Special Education Programs (OSEP). (1992). Fourteenth Annual Report to Congress on the Implementation of the Individuals with DisabilitiesEducation Act.Washington, DC: U.S. Department of Education.

Office of Special Education Programs. (1993). Fifteenth Annual Report to Congress on the Implementation of the Individuals with Disabilities EducationAct. Washington, DC: U.S. Department of Education.

Office of Special Education Programs. (1994). Sixteenth Annual Report to Congress on the Implementation of the Individuals with Disabilities Education Act. Washington, DC: U.S. Department of Education.

Office of Special Education Programs. (1995). Seventeenth Annual Report to Congress on the Implementation of the Individuals with Disabilities Education Act. Washington, DC: U.S. Department of Education.

Office of Special Education Programs. (1996). Eighteenth annual report to Congress on the implementation of the Individuals with Disabilities Education Act. Washington, DC: U.S. Department of Education.

Office of Special Education Programs. (1997). Nineteenth annual report to Congress on the implementation of the Individuals with Disabilities Education Act. Washington, DC: U.S. Department of Education.

Office of Special Education Programs. (1998). Twentieth annual report to Congress on the implementation of the Individuals with Disabilities Education Act. Washington, DC: U.S. Department of Education.

Office of Special Education Programs. (1999). Twenty-first annual report to Congress on the implementation of the Individuals with Disabilities Education Act. Washington, DC: U.S. Department of Education.

Office of Special Education Programs (2000). Twenty-second Annual Report to Congress on the Implementation of the Individuals with Disabilities Education Act. Washington, DC: U.S. Department of Education. 
Office of Special Education Programs. (2001). Twenty-third annual report to Congress on the implementation of the Individuals with Disabilities Education Act. Washington, DC: U.S. Department of Education.

Office of Special Education Programs. (2002). Twenty-fourth annual report to Congress on the implementation of the Individuals with Disabilities Education Act. Washington, DC: U.S. Department of Education.

Office of Special Education Programs (2003). Twenty-Fifth Annual Report to Congress on the Implementation of the Individuals with Disabilities Education Act. Washington, DC: U.S. Department of Education.

Office of Special Education Programs. (2004). Twenty-Sixth Annual Report to Congress on the Implementation of the Individuals with Disabilities Education Act. Washington, DC: U.S. Department of Education.

Office of Special Education Programs. (in press). Twenty-Seventh Annual Report to Congress on the Implementation of the Individuals with Disabilities Education Act. Washington, DC: U.S. Department of Education. [Annual report tables]. Retrieved April 20, 2005, from http://www.ideadata.org/tables27th/ar_ab2.htm

Rosenberg, M. S., \& Sindelar, P. T. (2005). The proliferation of alternative routes to certification in special education: A critical review of the literature. The Journal of Special Education, 39(2), 117-127.

Smith-Davis, J., \& Billingsley, B. S. (1993). The supply/demand puzzle. Teacher Education and Special Education, 16, 205-220.

Snyder. T. D., \& Hoffman, C. M. (2004). Digest of education statistics: 2003. Washington DC: National Center for Education Statistics, U.S. Department of Education.

Tourkin, S. C., Pugh, K. W,, Fondelier, S. E., Parmer, R. J., Cole, C., Jackson, B., et al. (2004). 1999- 2000 Schools and Staffing Survey (SASS) Data File User's Manual (NCES 2004-303). Washington, DC: U.S. Department of Education.

U.S. Department of Education. (2002). Meeting the highly qualified teachers challenge: The Secretary's annual report on teacher quality. Washington, DC: Author.

U.S. Department of Education. (2004a). Alternative routes to teacher certification [Forward]. Washington, DC: Author.

U.S. Department of Education. (2004b). Improving teacher quality state grants: Non-regulatory guidance. Washington, DC: Author. 